\section{JEFATURAS O ESTADOS. SOCIEDADES DE TRANSICIÓN EN LA CUENCA MEDIA DEL GUADIANA}

\section{CHIEFDOMS OR STATES. TRANSITIONAL SOCIETIES IN GUADIANA RIVER MIDDLE BASIN}

PABLO PANIEGO DÍAZ

PIF DEPARTAMENTO DE PREHISTORIA Y ARQUEOLOGÍA.

UNIVERSIDAD AUTÓNOMA DE MADRID

凶: pablo.paniego@hotmail.com

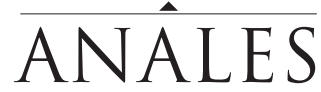

DE ARQUEOLOGÍA

C O R D O B E S A

NÚMERO 29 (2018)

\title{
RESUMEN
}

Durante la Edad del Hierro muchas de las sociedades se encuentran en un momento difícil de clasificar atendiendo a su estructura política, ya que las Jefaturas son cada vez más complejas y se acercan 0 alcanzan un grado de evolución tal que nos permite considerarlas estatales.

En este trabajo se ha puesto el foco en diferentes momentos en los que las poblaciones de la cuenca media del Guadiana pudieron alcanzar el desarrollo mínimo necesario para considerarlas sociedades estatales durante la I y II Edad del Hierro, antes de la conquista romana.

Palabras clave: Edad del Hierro; Edificios aristocráticos; Estado; Jefatura; Viriato.

\section{ABSTRACT}

Throughout Iron Age, many societies are difficult to classify according to their political structure because Chiefdom societies become increasingly complex, approaching or reaching an evolution status that allows us to consider them states.

This paper focus on different moments in which Guadiana's middle basin populations could have reached the minimum development necessary to consider them state societies during I and II Iron Age, before Roman conquest.

Keywords: Aristocratic building; Chiefdom; Iron Age; State; Viriathus

Uno de los retos más difíciles de resolver para la investigación actual es identificar el sistema político de las sociedades pretéritas, en parte debido a la necesidad de hacer clasificaciones discretas, como jefatura o Estado. Esta dificultad hace que, salvo contadas 
excepciones, la cuestión sea premeditadamente dejada a un lado, ya sea empleando eufemismos que no posicionen al autor 0 , directamente, ignorando la problemática, postura esta última que no es eximente, pues el mismo contexto termina por posicionar al investigador.

En este trabajo hemos escogido dos ejemplos, algo distanciados espacial y temporalmente, pero que representan los dos momentos que, antes de la conquista romana de la segunda mitad del siglo II a.C., pudieron suponer la transición de una sociedad de jefatura a una estatal. No obstante, hemos de tener presente que la línea que separa ambos modelos de organización política es difusa y muy tenue (Harris 1983: 120). Quizá, más que tenue, debemos considerar que el umbral de la estatalidad es ciertamente ancho y los mismos argumentos que sirven para hablar de la existencia de un Estado sirven para negar su emergencia, ya que, hasta cierto punto, todos los componentes cualitativos del Estado se hallan presentes en las jefaturas avanzadas (Harris 1983: 119-120). Por lo tanto, más que la existencia o no de determinadas características, es la intensidad de estas la que nos permitirá dividir a las sociedades entre estatales y no estatales.

Antes de analizar los ejemplos, creemos ineludible explicitar aquellas características que consideramos que diferencian a unas sociedades de otras, teniendo en cuenta que las definiciones que aportan los investigadores suelen ser panhumanas, ello quiere decir que se trata de modelos donde las particularidades y adaptaciones concretas no suelen estar definidas. Por lo tanto, nos encontramos con instituciones que, aunque universales, presentan una gran variedad de formas organizativas (Kristiansen y Larsson 2006: 24).

\section{JEFATURAS Y ESTADOS}

Hemos de tener en cuenta que si tan difícil es para la ciencia moderna clasificar como Estados o Jefaturas a sociedades coetáneas o temporalmente muy cercanas de las que poseemos abundante documentación, la tarea de catalogar a las sociedades conocidas arqueológicamente es harto difícil, tanto que algunos autores han abogado por abandonar dicha tentativa. Para unos, las clasificaciones antropológicas en bandas, tribus, caudillajes y estados oscurece más que aclara la situación social y política de la protohistoria europea (Wells 1988: 30), mientras que para otros la Arqueología no puede distinguir las distintas etapas (Service 1984: 327) debido a la inexistencia de puntos de cambio (Service 1984: 329). En esta línea se expresa también Fernández-Götz (2014: 61) cuando habla de la necesidad de fuentes escritas para estudiar los diferentes niveles sociopolíticos, pues es imposible hablar de magistrados, del funcionamiento de las relaciones de parentesco, etc. sin ellas. No obstante, creemos que huyendo del problema no logramos solucionarlo y, aunque sea con ciertas dudas y generando gran controversia, acercarnos a este asunto es la única manera de lograr un conocimiento real y profundo de las sociedades del Pasado. La Arqueología no debe contentarse con la mera descripción de diferencias materiales apreciables en determinadas construcciones o en ciertos objetos; debe perseguir una comprensión lo más completa posible de las sociedades pretéritas, las cuales estaban formadas por personas que 
interactuaban y no por bienes muebles 0 inmuebles.

Un primer punto a definir es la consideración de qué es el Estado y qué elementos lo definen. Nuestra propuesta se aleja de la postura defendida por Clastres (2014b), quien entiende por sociedades estatales aquellas en las que hay diferencias sociales. Por tanto, retrotrae prácticamente al Neolítico la existencia de sociedades estatales, y clasifica sin duda dentro de estas a las sociedades de jefatura o cacicazgo. Varios autores disienten de esta teoría pues fundamentan el origen del Estado en las mismas contradicciones internas de la sociedad provocadas por la desigualdad (Childe 1972: 115-116; Engels 1977: 212; Lull y Micó 2007: 248-249).

Como se señaló con anterioridad, Estado es un concepto complejo y sobre el que no existe consenso en cuanto a su definición. No solamente entre escuelas, sino que dentro de la misma corriente de pensamiento podemos encontrar definiciones en parte contradictorias. Por ello, vamos a explicitar qué consideramos nosotros como Estado, y, aunque asumimos que es una definición que no tiene por qué ser aceptada unánimemente, creemos que nos legitima para poder diferenciar, desde nuestra concepción, a aquellas sociedades que han alcanzado el rango de estatal de aquellas que se hallan dentro de los que en nuestra clasificación incluimos en sociedades de jefatura.

Respecto a estas últimas, las sociedades de jefatura 0 de cacicazgo ${ }^{1}$ se caracterizan por ser esencialmente redistributivas ${ }^{2}$, lo que a la larga conduce a formas de jerarquización rígidas y permanentes que culminan en un acceso diferencial a los recursos estratégi$\cos$ en las jefaturas avanzadas debido a sus sistemas de redistribución asimétrica (Alcina 1986). Estos casos en los que el agente redistribuidor se recompensa a sí mismo en primer lugar y en mayor medida siempre han precisado echar mano de ideologías y rituales para legitimar su apropiación de riqueza (Harris 1993: 28-33). Cuando este jefe tiene los medios materiales para obligar a sus seguidores a intensificar la producción y gradualmente deja de ser voluntaria la contribución, la jefatura se haya en el umbral del Estado (Harris 1982: 111).

En las jefaturas, el sistema era sancionado por la Mitología y por seres sobrenaturales, y el poder de las élites se suele legitimar por su origen divino (Service 1984: 111 y 299; Alcina 1986; Harris 1993: 28-33). Este gobierno teocrático sería, según Service (1984: 317), relativamente pacífico en cuestiones internas, en parte debido a que las ceremonias religiosas tratan de promover la sumisión de los comunes a las políticas y privilegios de la élite (Harris 1982: 121; Wagner 1990; Johnson y Earle 2003: 258261). La importancia de lo religioso es tal, en estas sociedades, que no parece haber diferencia entre las funciones seculares y sacerdotales, abarcando y recubriendo la religión todos los ámbitos y actividades (Service 1984: 319-320). Las ideologías son, por tanto, sistemas de creencias creadas y manipuladas estratégicamente por ciertos

1 El concepto de jefatura o cacicazgo es una abstracción en la que se engloba a sociedades que están evolucionando desde (y contienen elementos de) la colectividad del gran hombre o del grupo local hasta otras que se encuentran en los albores de la estatalidad (Johnson y Earle 2003: 255).

2 La redistribución se da cuando se entregan alimentos y otros objetos de valor a una figura de prestigio para que sean juntadas, divididas en porciones y distribuidas (Harris 1993: 16-19). 
sectores sociales, las élites, para establecer y mantener la legitimación de su posición en la sociedad (Johnson y Earle 2003: 269). Se trata de ideas rectoras que pretenden ocultar las contradicciones haciendo parecer coherente el sistema (de explotación), mostrándolas como inherentes a la naturaleza humana. Así, "las ideas dominantes en cualquier época no han sido nunca más que las ideas de la clase dominante" (Marx y Engels, 1977: 38).

La generación y acumulación de objetos suntuarios, que por definición han de ser escasos y difíciles de conseguir, son los exponentes de la acumulación de riqueza y poder, la encarnación y manifestación de la capacidad de unos seres humanos, cualitativamente distintos, para hacer cosas divinas (Harris 1993: 28-33; Kristiansen y Larsson 2006: 64). Su posesión genera un primer contraste entre élites y plebeyos (Harris 1982: 119120), ya que su movimiento se da habitualmente es una esfera separada de intercambio que los hace muy difícil obtener a cambio de bienes básicos (Johnson y Earle 2003: 267). Esta distinción generada por la economía basada en la riqueza es la base de la diferenciación social, que era inexistente cuando dominaba la economía doméstica y se tenía el derecho al beneficio completo de lo producido o creado mediante el control total del proceso de elaboración (Sahlins 1972: 120121; Johnson y Earle 2003: 268). Ahora el simple productor se ve en la necesidad de expandir sus objetivos productivos para cubrir las demandas de la economía política regional, generalmente en forma de pago a las élites (Johnson y Earle, 2003: 265-266).

De esta forma, tenemos una sociedad estratificada, lo que significa que los diferentes miembros disfrutan de manera diferencial de los derechos de acceso a los productos básicos necesarios para la vida. Ello requiere una organización formal del poder, cuyo fin es proteger (y a veces extender) la estratificación (Fried 1978: 36; 1979: 141). En las jefaturas complejas ya se cuenta con al menos un primer nivel de estratificación con una división en dos clases: dirigentes y productores (Fried 1979: 142; Johnson y Earle 2003: 258-261). Además, en determinado momento, estas sociedades de jefatura institucionalizan la herencia de la posición social, siendo la primogenitura casi universal (Service 1984: 93), aunque en su defecto se dará siempre dentro de un linaje familiar (Harris 1982: 114; Fernández-Götz 2014: 55).

Respecto a los restos materiales, más allá de los bienes de prestigio con un acceso restringido que nos permiten hablar de diferentes escalas dentro de la sociedad, lo más habitual es contar con una serie de asentamientos, en diferentes ubicaciones y con desiguales características, que los arqueólogos tendemos a clasificar dentro de distintas categorías. Habitualmente, un nivel de análisis posterior busca la jerarquización de estos, y aunque puede ser una herramienta útil a la hora de acercarnos a la organización política (Parkinson y Galaty 2007: 115-116), hemos de tener en cuenta que ni la jerarquización de los asentamientos sirve para hablar de Estado per se, ni la ausencia de ciudad implica necesariamente la ausencia de Estado (Wagner et alii., 1996), ya que la ciudad no crea el Estado (Service 1984: 304-305). Territorialmente, el patrón de asentamientos de las jefaturas es variable, aunque parece habitual que se siga un modelo por el que hay cierta concentración de la población en el centro redistribuidor que ejerce su poder sobre los 
núcleos aldeanos dispersos, dependientes y subordinados (Alcina 1986; Wagner 1990).

Como hemos advertido, la línea entre la Jefatura compleja y el Estado parece ser muy ancha y las sociedades de transición son ciertamente difíciles de clasificar. Por ejemplo, Lull y Risch (1995: 98) afirman que "una sociedad de jefatura que se beneficia y/o implementa sistemas de explotación económicos podría ser considerada una forma de gobierno estatal". En la misma línea se manifiestan Ruiz y Molinos (1988: 57) cuando clasifican como estados las jefaturas cuya organización de la descendencia se enmarca en la definición de clan cónico ${ }^{3}$. De esta forma, las sociedades de jefatura complejas serían consideradas por estos autores como sociedades estatales.

Un ejemplo de lo difícilmente discernible que pueden ser ambos tipos de sociedades lo podemos ver en los zulúes precoloniales, cuyo estado mantenía muchos de los aspectos de las jefaturas en las que estaba basado (Service 1984: 125-137; Lewellen 2009: 63). Quizá fuera su brevedad uno de los factores causantes de ello, lo que unido a las características de su emergencia precipitada por la presencia de colonos europeos en sus límites hace de este estado un auténtico ejemplo de sociedad estatal muy poco desarrollada y diferenciada respecto al modelo anterior, tanto que los mismos zulúes parecían considerar su estado como una jefatura glorificada (Lewellen 2009: 62).

Bajo determinadas circunstancias, algunas jefaturas complejas dan el salto y cruzan la tenue, aunque ancha, línea divisoria que nos permiten considerarlas estatales. No obstante, hemos de recordar que la inmensa mayoría de las jefaturas avanzadas no llegan a convertirse en estados (Harris 1982: 120), por lo que no planteamos teleológicamente esta cuestión. En estas jefaturas que se encuentran en el umbral de la estatalidad, el jefe tiene un control institucionalizado suficiente sobre la organización económica y política de su sociedad para poder restringir el liderazgo a un segmento de la élite. Este control económico puede derivar del almacenamiento central de excedentes, el control tecnológico, la situación de guerra en regiones naturalmente circunscritas o el control del comercio exterior (Johnson y Earle 2003: 312-313).

La causa principal del surgimiento de Estado es mantener un sistema basado en las desigualdades económicas que divide en clases la sociedad mediante la explotación (Childe 1972: 115-116; Engels 1977: 212; Lull y Micó, 2007: 247-249). Esta condición es necesaria pero no suficiente y se han de dar simultáneamente ciertas situaciones demográficas, tecnológicas, económicas y ambientales (Harris 1982: 111). Para transitar de la jefatura al Estado se necesita una base energética amplia (como un sistema mixto cerealístico-ganadero) que permita generar los suficientes excedentes, mediante la intensificación, para mantener un cuerpo policiaco-militar, una alta densidad de población, oportunidades para un control económico suficiente como el anteriormente descrito y cierta circunscripción social-ambiental que provoque que la huida de los dependientes suponga el empeoramiento de su situación (Carneiro 1970; Harris 1982: 120-121; Johnson y Earle 2003: 340). Asimismo, la transmisión del poder ha quedado institucio-

3 El clán cónico es un grupo de descendencia común jerarquizado y segmentado, ver Sahlins, 1977: 80-81. 
nalizada y centrada en un pequeño número de individuos vinculados por parentesco.

Para Service, en cambio, este proceso se desarrolla "de manera natural", es un paso más en un continuo, pues cuando una institución de tipo aristocrático hereditaria se mantiene suficiente tiempo en el poder como para legitimarse se trata de un verdadero gobierno (Service 1984: 330) pues la lucha de clases es inexistente (Service 1984: 308).

Estos requisitos y factores limitadores suelen ser válidos para los Estados prístinos, los cuales son muy reducidos en número. Pese a que contamos con un posible Estado prístino en la Península Ibérica (Lull y Risch 1995), su devenir se vio frustrado y su influencia no habría de dejarse notar sobre las sociedades de la Edad del Hierro en el Suroeste.

Los modelos de emergencia de los Estados secundarios, así como sus características, han despertado menos interés en la investigación (Lewellen 2009: 90). Según Price (1978), la emergencia de los Estados secundarios, que no responderían a un patrón universal, implica una fuerza externa impuesta, abierta o velada. Se forman siguiendo dos modelos, por un lado como continuadores de uno anterior o desarrollándose sobre los restos de entidades más grandes. Por otro lado, pueden surgir como consecuencia de encontrarse en los límites de una entidad estatal que se expande por las tierras ocupadas por sociedades sin estado, ya sea de forma directa o indirecta, en este caso mediante la alteración del medio socioeconómico que crea las condiciones de la transformación (Childe 1972: 157-161; Price 1978; Parkinson y Galaty 2007). En ambas situaciones suelen usar parte o toda la organiza- ción del Estado anterior como modelo (Fried 1978: 37) y las élites habitualmente toman prestados elementos simbólicos y materiales (Parkinson y Galaty 2007), lo que genera un nuevo tipo que no es una simple copia sino una adaptación a un nuevo ambiente (Childe 1972: 161).

De esta forma, el surgimiento de los Estados secundarios no depende tan directamente de algunos elementos como los prístinos, aunque hay determinados factores que son fundamentales para que logren transitar con éxito desde la sociedad de jefatura a la estatal. Estos son: un determinado número de habitantes, un nivel tecnológico y productivo y, en cierta medida, algún tipo de circunscripción que impida o limite el éxodo.

Una vez vista la emergencia de este tipo concreto aunque diverso de entidad, cabe definir qué elementos los caracterizan. Pese a que cuenta con varios años, la definición en 7 puntos de Claessen y Shalník (1978) sigue siendo una excelente síntesis de los requisitos mínimos necesarios para considerar un sistema como de tipo estatal: población suficiente que haga posible la categorización, estratificación y especialización que, no obstante, es un dato muy relativo y que variaría mucho según la sociedad; la ciudadanía la determina la residencia y no el nacimiento; gobierno centralizado con poder soberano para el mantenimiento de la ley y el orden a través del uso de la autoridad, la fuerza o la amenaza de ésta que también se impone sobre fuerzas centrífugas; es independiente y en todos los casos hay un ejército o cuerpo de guardia personal, además, el Estado monopoliza la fuerza en nombre del gobierno del Estado; hay un excedente regular; existe una estratificación social en al menos dos grupos, 
gobernantes y gobernados; y, finalmente, hay una ideología común sobre la que descansa la legitimación del estrato superior.

Como podemos ver, esta definición se distancia en parte de la dada por Childe, mucho más perceptible a partir del registro material (a partir de Lull y Micó, 2007: 198-200) que se basa en: existencia de urbanismo; construcción de edificios públicos monumentales; invención de un sistema de registro (escritura); desarrollo de las ciencias exactas y predictivas; desarrollo del arte; intercambios a larga distancia.

Ambas definiciones tienen la necesidad de concentración de excedentes, la existencia de una amplia división del trabajo que genera un grupo de no productores mantenidos por los excedentes, la existencia de una clase social dominante y el hecho de que la ciudadanía esté basada en la adscripción residencial más que en el parentesco. A ellas podemos sumar la ideología, cuya representación material suelen ser las construcciones públicas de las que hablaba Childe, cuya construcción, aunque costosa, sirve para convencer a las clases subalternas de que las élites controlan, en beneficio de todos, las fuerzas naturales y sobrenaturales (Harris 1982: 121). A estos elementos, Parkinson y Galaty (2007: 115-116) suman la existencia de 4 niveles de jerarquía de asentamiento, lo que incluye 3 niveles en la toma de decisiones y que la residencia oficial del gobernante sea un palacio, algo que ya apuntó Price (1978) cuando planteaba como un indicador para "detectar" la diferenciación socioeconómica la cantidad de energía representada en la vivienda de la élite frente a la que se detecta en la del común.
Como hemos visto, el poder de las élites se sustenta en el control económico, ello posibilita, y de hecho es frecuente, que en los estados haya poblaciones étnicamente distintas (Service 1984; Johnson y Earle 2003: 315).

Ante la dificultad de detectar a nivel arqueológico muchos de estos elementos, Lull y Micó (2007: 256-257) proponen que la búsqueda del Estado es la búsqueda de las categorías claves del Estado: explotación económica, clases sociales y fuerza coercitiva. Aunque este último punto estaría hasta cierto punto limitada por las élites locales, pues como muestra el ejemplo de la Roma republicana, los clanes tradicionales mantenían un importante poder militar (Motta y Terrenato 2006).

Finalmente, no debemos despreciar el elemento temporal como definidor de una estructura estatal. Esto quiere decir que, para defender la existencia de un Estado, debe haber cierta continuidad (Service 1984: 330). Como se ha argumentado anteriormente, casi todas las características del Estado están en las sociedades de jefatura avanzadas, y en algunos casos éstas pueden ir un paso más allá, pero no es extraño, de hecho es habitual, que no logren cruzar el umbral de estatalidad (Harris 1983: 120), siendo común que haya mecanismos dentro de la sociedad para evitar que haya una evolución en este sentido (Clastres 2014b).

\section{LA I EDAD DEL HIERRO}

Dentro de la I Edad del Hierro de la cuenca media del Guadiana asistimos a diferentes momentos, en gran medida identificados por 
los cambios en los patrones de ocupación. Más allá de las disquisiciones sobre la nomenclatura más apropiada a emplear con esta sociedad, podemos definirla como una sociedad polarizada, donde un pequeño grupo de personas acumula la riqueza y la inmensa mayoría se encuentra en una situación de privación de esa capacidad acumulativa. Esta diferencia social parece que fue la tónica común del Hierro I en el Guadiana Medio, aunque cabe la posibilidad que existiesen grados de intensidad. Este momento histórico se ha definido en gran medida, como se advirtió anteriormente, por la tipología de los asentamientos, que define dos grandes etapas. La segunda de ellas, a partir de finales del siglo VI a.C., se caracteriza por la inclusión de un nuevo tipo de asentamiento (Rodríguez González 2016: 443), los edificios aristocráticos. De esta forma, por un lado, se cuenta con una serie de asentamientos rectores, aglomeraciones (proto)urbanas que algunos autores identifican, creemos que tergiversando el término, como oppida (Almagro 2008a, 2008b y 2008c; Rodríguez Díaz et alii 2009: 205-206). Estos asentamientos tendrían una prolongada ocupación como los ejemplos bien documentados de Badajoz (Berrocal-Rangel, 2008), Lobón ${ }^{4}$ o Medellín.

Tras los trascendentales cambios que se viven a todos los niveles hacia el 400 a.C., destaca un elemento de continuidad, la de estos sitios en altura en las inmediaciones del Guadiana, pese a que en algunos casos se constaten destrucciones, como en el Tam-

\footnotetext{
4 Las excavaciones realizadas a los pies del asentamiento han deparado restos que nos permiten afirmar una ocupación durante la I y la II Edad del Hierro, aunque se desconoce si hubo continuidad o en algún momento el hábitat fue abandonado y posteriormente refundado. J. A. Salgado Carmona, comunicación personal.
}

borrío (Walid y Pulido 2013), donde parece que su ocupación continúa (Rodríguez Díaz et alii 2011), aunque con un hiato (Rodríguez González 2016: 878). Conviviendo temporalmente con estos asentamientos, se documentan numerosos edificios aristocráticos que salpican las tierras ribereñas del Guadiana y que, incluso, se expanden varios kilómetros lejos de este curso de agua (Fig. 1). Completarían la nómina de tipos de asentamientos las pequeñas unidades de hábitat y explotación del territorio clasificadas como granjas, caseríos o cortijadas pero que remiten en el fondo a un mismo tipo se asentamiento. Por otro lado, los grandes poblados abiertos en Ilano, como El Palomar (Jiménez Ávila y Ortega 2008) o La Veguilla (Rodríguez Díaz et alii, 2009: 214) parece que no tuvieron por regla general continuidad en esta fase final, siendo una posible excepción el Cerro de la Barca-Torruco que podría corresponderse a este momento y que se ha interpretado como un núcleo dependiente del Tamborrío (Rodríguez González 2016: 838848). De esta forma nos encontramos con 4 niveles como mínimo en la jerarquía de los asentamientos, que como señalan Parkinson y Galaty (2007: 115-116) es uno de los elementos que distinguen a las jefaturas de los Estados.

Una de las manifestaciones materiales que permite acercarnos a la diferenciación social y el tipo de organización política que rige estas sociedades es el mundo funerario. El problema es que la mayor parte de la información proviene de un único yacimiento, el de Medellín. Dicha necrópolis es para algunos autores la correspondiente al asentamiento en alto que se ubicaría en el cerro que domina la villa (Almagro 2008), idea contestada recientemente por Rodríguez 


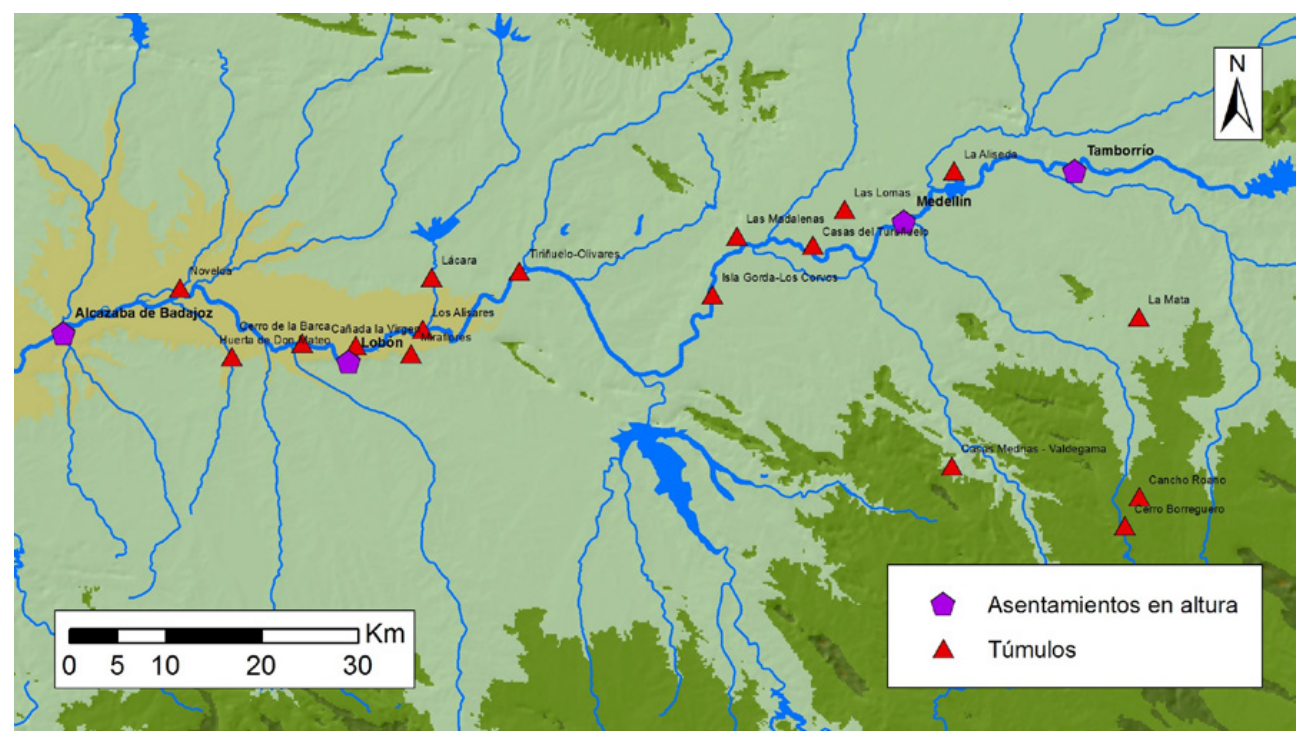

Fig. 1. Asentamientos en altura y edificios aristocráticos del Guadiana Medio (elaboración propia a partir de Rodríguez González 2016).

González (2016: 400), quien defiende que en ella, así como en las necrópolis cercanas, se enterrarían todas las poblaciones de la comarca, con un carácter que trasciende el uso gentilicio de la necrópolis (Rodríguez González 2016: 877). Frente a esta idea, otros autores sostienen que La Veguilla-6 se asociaría al sitio de La Veguilla (Rodríguez Díaz et alii 2009: 199) o Valdelagrulla a algún caserío desconocido o al propio sitio de Medellín (Menéndez et alii 2013), idea esta última que parece más acertada vista la riqueza documentada. Independientemente de ello, lo que no cabe duda es que en estas necrópolis del entorno del actual Medellín se documenta una clase social que ha sido identificada con una élite urbana (Almagro 2008: 941), que vive una crisis demográfica en el último siglo de existencia.

Ante la pregunta de qué estructura política se desarrolló en la cuenca media del
Guadiana durante el Hierro Antiguo, merece la pena repasar qué posturas han sido defendidas a este respecto para las dos grandes etapas definidas, los siglos VII-VI a.C. y finales del VI-V a.C.

Por un lado, contamos con varios grupos de investigación que sin lugar a dudas señalan que, al menos para el caso de Medellín, la estructura política que regía a la sociedad tenía un tinte estatal; así lo explicita Almagro y su equipo (2008a) bajo el sugerente título de Medellín y su territorio como ciudad-estado o Rodríguez Díaz (2009: 74, 118-123 y 176180; Rodríguez Díaz et alii 2009: 207-212) cuando afirma que el oppidum de Medellín se convirtió en un centro político a partir de mediados del siglo VII a.C., en una suerte de "capital del valle", donde imperaba un modelo organizativo piramidal con el poder concentrado y de carácter protoestatal regido por una autoridad suprema (régulo o déspota- 
monarca), propietaria de la tierra, el trabajo y el excedente, pudiéndose clasificar el modo de producción desarrollado como asiático. Pese a mostrarse cauto y emplear el sufijo proto-, podemos ver que todos los elementos que emplea para definir la sociedad se enmarcan dentro de nuestra definición de Estado. Ambas posturas, sin embargo, se distancian cuando tratan las últimas décadas del siglo VI y el V a.C., pues mientras que para Almagro y su grupo este sistema jerarquizado y estatal pervive hasta su desaparición en la transición a la II Edad del Hierro, el equipo de la Universidad de Extremadura, encabezado por Rodríguez Díaz, plantea la posibilidad de que el poder se disgregase en un modelo más heterárquico. En este, el poder se repartiría entre las antiguas élites urbanas y los nuevos señores del campo, residentes en los edificios aristocráticos y que tendrían un carácter independiente, siendo la sociedad de tipo caciquil o de jefatura (Rodríguez Díaz 2009: 179-180), pese a que sostiene que dichas élites tendrían pleno control y uso de la tierra, siendo un verdadero dominio señorial (Rodríguez Díaz 2009: 155-156) y que por sus características no se diferencia del modelo defendido para los siglos VII-VI a.C. salvo en su escala. En la misma línea de la heterarquía parecen posicionarse Celestino (2011-2012: 301-302) y Jiménez Ávila (2001; Jiménez Ávila y Ortega 2008). Este último considera los edificios aristocráticos como centros de poder aislados que capitalizan un entorno rural fuertemente explotado, coincidiendo con la ausencia de verdaderas

\footnotetext{
5 En muchos casos las antiguas jefaturas se centran en lo religioso, el lugar donde encuentran "refugio" cuando son despojados del poder político y económico por estructuras mayores, quienes aunque lo cedan son los auténticos poseedores de él.
}

élites urbanas fuertes y consolidadas (Jiménez Ávila 2016: 46-47). Para el caso concreto de Cancho Roano defiende un culto privado de tipo gentilicio (Jiménez Ávila 2001), asociado y restringido a la familia aristocrática, al menos así sería en sus fases finales tras las reformas del edificio que privatizan este espacio (Jiménez Ávila 2005). Volviendo a las tesis de Almagro et alii (2008c), nos encontramos con que los edificios aristocráticos son catalogados como palacios fortificados con una función productora y de control, dominados por élites gentilicias de carácter sacro ${ }^{5}$ que controlan los medios de producción pero que son dependientes de los grandes centros como Medellín. Un elemento interesante a señalar de la tesis de Almagro respecto a Medellín es su carácter de colonia tartésica, lo que implicaría la implantación de un modelo alóctono y que nos permite clasificar a este estado secundario como surgido por la acción directa de una entidad estatal sobre un territorio limítrofe.

Por otro lado, Rodríguez González apuesta por dejar "al margen una terminología que puede llegar a ser en muchos casos engañosa" (Rodríguez González 2016: 883). Afirma que el modelo jerárquico no es del todo satisfactorio, negando que fuesen dominados los edificios aristocráticos desde el, según ella, inexistente oppidum de Medellín (Rodríguez González 2016: 359 y 457-460) o cualquiera de los asentamientos en altura, ya que su papel predominante se basa exclusivamente en su situación (Rodríguez González 2016: 361) y defiende la ausencia de argumentos para defender un modelo regentado por ciudades-estado en el Guadiana Medio (Rodríguez González y Celestino 2017a: 233). Pese a ello, su propuesta teórica no dista en exceso de las anteriormente mencionadas 
que elevan al rango de la estatalidad a estas sociedades de finales de la I Edad del Hierro, ya que habla de un control político indirecto fundamentado en la centralización y redistribución de excedentes, así como de una serie de asentamientos en alto de menor entidad que el Tamborrío cuya función sería controlar el paso del río y que parece que dependerían de él al encontrarse dentro de su territorio político, aunque se muestra cautelosa en este punto y cree prematuro darle un papel preponderante (Rodríguez González y Celestino 2017a: 233). Por otro lado, sostiene que la construcción de los edificios aristocráticos fue promovida por el asentamiento de Tamborrío para que hicieran de una suerte de intermediarios en el control de la tierra y que había una complementariedad de funciones entre ellos y el asentamiento principal (Rodríguez González 2016: 880-882), lo que haría encajar esta teoría dentro del modo de producción tributario ${ }^{6}$, al igual que las defendidas anteriormente.

Más allá del difuso territorio del Guadiana Medio tratado, nos encontramos con realidades completamente diferentes y que responderían a otros sistemas de organización, como en el centro-sur portugués (Mataloto 2008), las áreas poco aptas para la agricultura (Sanabria 2008) o el Sur de Badajoz (Pavón et alii 2015: 100), donde se ha hablado de una heterarquía desestructurada propia de zonas marginales, por lo que no podemos reducir la cuestión e igualar la cultura tartésica con un sistema político concreto, pues no hemos de olvidar que por regla general, especialmente en las sociedades preestatales, las entidades políticas son siempre menores que las culturas y redes que las definen (Kristiansen y Larsson 2006: 66). En estos últimos casos el sistema político sería sin lugar a dudas de tipo caciquil o de jefatura, aunque el grado de complejidad de esta, que variaría en escala según las zonas, sería en todo caso menor que los posibles sistemas de jefatura desarrollados en el territorio en el que se centra este trabajo. Dependiendo del territorio de Medellín y de las otras cabeceras estatales, este modelo en cierto modo ácefalo o heterárquico del Sur de Badajoz pudo darse en otros territorios, como, por ejemplo, los entornos de La Mata o de Cancho Roano, siendo una posible explicación del surgimiento de los edificios aristocráticos más alejados la presión de los estados del entorno, ya que las posibles capitales estatales se encuentran muy alejadas (más de $30 \mathrm{~km}$ desde el Tamborrío o Medellín), demasiado para que pudieran pertenecer a su territorio político (Celestino 2011-2012: 301). No obstante, este modelo de emergencia independiente puede no ser válido para todos los sitios, pues algunos se encuentran a pocos kilómetros de los asentamientos en altura, lo que nos plantea la posibilidad de que en estos casos sí fuera un origen promovido, o al menos permitido, desde los centros rectores, lo que nos llevaría a aceptar un modelo estatal para las fases finales. Otra posibilidad es que su surgimiento coincida con el fin del poder hegemónico de estos centros urbanos y el sistema inaugurado en la periferia aproveche el colapso del modelo estatal, lo que explicaría la antigüedad de alguno de estos edificios aristocráticos situados en territorios alejados del Guadiana como el Cerro Borreguero (Ce-

6 El modo de producción tributario, que incluiría los marxianos asiático y feudal, da acceso al productor primario a los medios de producción, a la vez que, por medios políticos o militares, se les saca tributo. Hay una amplia gama de posibilidades, desde fuertes élites centrales hasta modelos donde las escalas intermedias tienen un gran poder (Wolf 2005: 105-106). 
lestino y Rodríguez González 2017), el cual anticiparía las dispersión de poderes y el surgimiento de un nuevo modelo político.

Volviendo a la posible crisis política de finales del siglo VI a.C., si el estado capitalizado por las élites aristocráticas residentes en Medellín se disgregó políticamente en otras entidades menores, estamos ante una crisis del modelo, pues no hemos de olvidar que la fisión no forma parte del proceso normal de la actividad política del Estado como sí que lo es en otro tipo de sociedades (Chamorro 1991: 179; Lewellen 2009: 61). A favor de la tesis de la heterarquía se cuenta el menor desarrollo de la necrópolis de Medellín en esta fase (Rodríguez Díaz et alii 2009: 212218), la ausencia de evidencias de un control directo por parte de alguno de los sitios en altura sobre los edificios aristocráticos y, además, la crisis del modelo del siglo VII-VI a.C. tendría su eco en el fin de varios grandes asentamientos aldeanos en Ilano a finales de este momento (Rodríguez Díaz et alii 2009: 214). Si se acepta esta nueva situación nos hallamos ante una problemática en la que cabe preguntarse si el sistema estatal se perpetúo con una nueva distribución del poder o si aparecieron pequeños mini-estados que en la práctica supondrían una regresión del sistema a la categoría de sociedad de jefatura, coincidiendo con un proceso de descentralización, algo que, por otro lado, es habitual en la Edad del Hierro europea (FernándezGötz 2017). Dicho proceso podría bien estar relacionado con la resistencia a la formación de sistemas más centralizados y desiguales asociados a la estatalidad.

Un problema fundamental a la hora de abordar esta cuestión y decantarnos por alguno de los dos modelos propuestos, que ayudaría asimismo a responder a la pregunta de cuál es su forma de organización política, es lo difícil que es definir los límites regidos por determinadas élites, ya que, en ausencia de informaciones escritas, la delimitación de entidades políticas que trascienden los asentamientos y sus áreas de influencia inmediata siguen siendo uno de los mayores retos de la investigación (Fernández-Götz 2014: 6162).

Abundando en la función de los edificios aristocráticos que suponen una novedad a escala territorial en el sistema, parece unánimemente aceptado que entre sus funciones estaría el acaparamiento y redistribución de los productos agropecuarios, de entre los cuales debemos prestar especial importancia a los cereales y legumbres, ya que son susceptibles de ser almacenados, convirtiéndose en una excelente moneda de cambio de las élites. Merece la pena plantear la hipótesis de que el recipiente de grandes dimensiones documentado en las excavaciones de Casas del Turuñuelo (Guareña, Badajoz), y que ha sido identificado como contenedor de líquidos o incluso un posible sarcófago (Rodríguez González 2016: 796; Rodríguez González y Celestino 2017b), tuviera como funcionalidad contar el grano entregado a modo tributo. No está de más recordar que el almacenamiento y redistribución de excedentes no es propio únicamente del Estado y se da también entre las Jefaturas.

Una vez hecho este sucinto repaso historiográfico, creemos que es momento de valorar los datos que se poseen insertándolos en el modelo de sociedad estatal que se expuso con anterioridad. El primer punto a destacar es que se trataría de un tipo de estado de carácter secundario, ya fuera de primera 0 
de segunda generación, en este último caso si se acepta la colonización tartésica planificada propuesta por Almagro (2008b: 10551059), quien incluso plantea a Carmo como metrópoli de Medellín.

Algunas de las características identificativas de los estados, como la existencia de un determinado número de habitantes que permitiera la estratificación y la especialización, sí que parece cumplirse a tenor de dos elementos indicativos: la profusión de asentamientos de la I Edad del Hierro en este territorio, generalmente de pequeño tamaño, que contrasta con el relativo vacío anterior (Rodríguez Díaz et alii 2004 y 2009; Walid y Nuño 2005; Sanabria 2008; Sevillano et alii 2013) y, por otro lado, la existencia de elementos artesanales de gran calidad, aunque en muchos casos se trata de bienes de importación (Rovira et alii 2005). El aumento de pequeños y grandes asentamientos rurales se ha vinculado con una colonización agraria (no necesariamente dirigida) que generaría un excedente regular de productos agropecuarios $^{7}$, el cual sería usurpado por un grupo cuyos miembros tendrían un acceso diferencial a ciertos recursos como demuestran los restos de las necrópolis o las propias diferencias en las construcciones excavadas hasta la fecha. Difícilmente discernible arqueológicamente es la existencia de una ciudadanía basada en la residencia y no en el parentesco y de un gobierno centralizado que monopolizase el ejercicio de la violencia y con derecho para cobrar impuestos y que, asimismo, fuera independiente. Son estos factores, prácticamente invisibles en la materialidad, lo que lleva a algunos autores a negar la Arqueología como medio de acercarnos al tipo de organización política en ausencia de fuentes escritas. El último punto de la clasificación de Claessen y Shalník, la ideología, sí que tuvo su reflejo material en la construcción de edificios específicos. Un ejemplo podría ser Cancho Roano, donde el elemento sagrado legitimaría el sistema, aunque parece que progresivamente esta legitimidad requeriría un menor recubrimiento religioso, lo que explica la privatización creciente del espacio dedicado a tal fin. Además, si seguimos las valoraciones de Parkinson y Galaty (2007) y Price (1978), vemos que hay una importante diferencia en la inversión realizada en las construcciones del común y las de la élite.

Si atendemos a la propuesta de Lull y Micó (2007) sobre qué elementos buscar para poder hablar de sociedades estatales, vemos que los requisitos se cumplen, pues hay, sin duda, al menos dos clases sociales, una de cuales explota económicamente a la otra. Esta explotación estaría sustentada por una fuerza coercitiva, ya estuviera enmascarada por el factor religioso o por la violencia física ${ }^{8}$, que, no obstante, es más difícil de rastrear arqueológicamente.

Como conclusión, podemos afirmar que, de forma explícita o velada, todos los autores parecen estar de acuerdo en que durante los siglos VII-VI a.C. se desarrolló en la cuenca media del Guadiana uno o varios sistemas

7 Una muestra del control centralizado de al menos parte de la producción puede verse en el granero de grandes dimensiones documentado en El Palomar, o las zonas de almacenaje de los edificios aristocráticos.

8 Las armas no debieron formar parte del ritual funerario y es por ello que su número es muy reducido en las necrópolis. En cambio, en Cancho Roano se han recuperado un mínimo de 24 puntas de lanza y un soliferrum junto a los restos de algunos y escudos y vainas y una posible espada (Kurtz 2003). Además, no hay que olvidar el abandono planificado de estos sitios, lo que podría reducir el número de armas potencialmente recuperables en la intervención arqueológica. 
políticos que encajarían en las tradicionales definiciones de sociedad estatal, que en este caso sería también urbana. Más controversia suscita el final del Hierro Antiguo, que abarca finales del siglo VI y el V a.C., cuando tras una serie de transformaciones aparecen nuevas realidades que hacen dudar a algunos investigadores sobre la entidad de las élites rectoras del nuevo modelo propuesto, ya que la jerarquía ha dado paso a un sistema más heterárquico. En este nuevo tiempo pudo haber pequeñas unidades políticas que, aunque conservasen parte de la parafernalia y la ideología heredada-imitada, por sus dimensiones y capacidades parecen poder insertarse en un sistema de jefatura 0 , cuanto menos, paraestatal ${ }^{9}$. Cabe la posibilidad de que ante lo que nos encontramos sea la convivencia de varios sistemas de organización política en un mismo territorio a causa de la incipiente y poco madura estructura estatal que no tuvo la capacidad para expandirse y modificar el resto de sistemas, lo que nos hablaría de una dispersión de poderes y estructuras en un tiempo de transición. Esto nos demuestra que la postura telelológica de que las sociedades quieren avanzar no siempre se cumple.

Por otro lado, aunque no hay declaraciones explícitas, salvo contadas ocasiones, todos los autores parecen inclinarse por la defensa de un modo de producción tributario en estos sistemas políticos. Este sería de tipo fragmentario, lo que acercaría el modo de producción existente al de tipo feudal de la teoría marxista, pese a que Rodríguez Díaz sostenga que hubo un modo de producción

\footnotetext{
9 Aunque siguiendo las definiciones de Ruiz y Molinos (1988: 57) y Lull y Risch (1995: 98) mantendrían su categoría de sociedades estatales.
}

asiático, pues no contamos con datos que refrenden el control de algún elemento estratégico en el proceso de producción, como obras hidráulicas, que restringiese completamente el acceso a los medios de producción de las clases subalternas.

\section{VIRIATO Y LOS CELTO-LUSITANOS}

En este segundo ejemplo nos hemos centrado en las sociedades limítrofes del territorio conquistado y dominado por Roma a mediados del siglo II a.C. Si bien es cierto que las relaciones entre ambos colectivos fueron fluidas durante toda la primera mitad del siglo, generalmente en forma de confrontación armada, se intensificaron en la Período de los Caudillos (155-138 a.C.). Estos suelen aparecer mencionados por las fuentes exclusivamente como cabecillas militares de bandas de salteadores que asolaban a las "pacíficas gentes" sometidas a Roma. La aparición de Viriato supuso un paso más en esta sociedad de frontera, acaso un paso ineludible vista la situación anterior. No obstante, la muerte de Viriato y la inmediata conquista romana truncaron los cambios que parecían estar gestándose en el seno de la sociedad celto-Iusitana de la frontera romana.

En este segundo caso de estudio, a diferencia del anterior, el grueso de los datos procede de fuentes escritas, por lo que nos otorga unas informaciones que el registro arqueológico es incapaz de producir, como bien ha señalado Fernández-Götz (2014:61). Sin embargo, el limitado número de datos arqueológicos nos priva a su vez de otra serie de elementos importantes para acercarnos 
con una perspectiva amplia y un importante corpus de datos al tipo de organización sociopolítica de estas poblaciones en los momentos inmediatamente anteriores a su conquista por Roma. No obstante, sabemos que se trata de una sociedad cualitativamente distinta y que el modelo social y político no fue una continuación del anterior y cuyo devenir tampoco guarda un intenso paralelismo.

Aunque adelantemos los acontecimientos, creemos que es necesario incidir que los territorios más directamente implicados en la Guerra de Viriato son las tierras meridionales de Extremadura y la serranía onubense, lo que se conocerá en época imperial como Baeturia, así como el Alentejo; un territorio que se ha mostrado más coherente para situar las acciones y el origen del grueso de las poblaciones enfrentadas a Roma, las cuales aparecen denominadas en las fuentes como lusitanas aunque arqueológicamente se las ha igualado con célticos y túrdulos (BerrocalRangel 1992; 1998; Pérez Vilatela 2000; Salinas 2008; Paniego 2017; Sánchez Moreno e.p.). Para evitar confusiones y distinciones basadas en la disciplina desde la que se estudian los sucesos creemos adecuado el empleo del concepto celto-Iusitano para definir a estas poblaciones que ocupan el territorio definido entre Sierra Morena Occidental y el Guadiana (Berrocal-Rangel 1992; Paniego 2017).

Arqueológicamente nos encontramos ante un patrón de ocupación del territorio que difiere completamente del conocido en la I Edad del Hierro ${ }^{10}$. De hecho, se da la particularidad en las tierras meridionales del Guadiana Medio de que las zonas con mayor ocupación durante el Hierro Antiguo pasan a estar prácticamente despobladas en estos momentos y viceversa, y salvo los asentamientos en altura tipo Tamborrío o la Alcazaba de Badajoz no se ha constatado continuidad en la ocupación. La hipótesis de Pérez Macías (1996) de que las nuevas poblaciones se asientan y se hacen hegemónicas culturalmente donde había un vacío o una baja densidad poblacional parece corresponderse con la realidad, al menos en el sector occidental de la futura Beturia (grosso modo cuenca del Ardila y serranía onubense), donde se asientan lo que arqueológicamente se han definido como célticos (Berrocal-Rangel 1992), cuya cultura también se expande al centro-sur portugués. Por otro lado, los datos sobre los túrdulos son más que escasos y apenas contamos con yacimientos conocidos ocupados antes de la Conquista romana (Berrocal-Rangel 1998; Rodríguez Díaz y Enríquez Navascués 2001; Paniego 2014). De hecho, solamente hay niveles prerromanos documentados mediante excavación arqueológica en un pequeño asentamiento en las inmediaciones de Cancho Roano con una cultura material donde se aúnan influencias meseteñas y meridionales (Sanabria et alii 2013) y de una cronología posiblemente anterior al contacto con púnicos y romanos de la región; el enclave fronterizo entre túrdulos y célticos de Castillejos II en Fuente de Cantos (Rodríguez Díaz 1987: 45-204); el castro de La Mesilla de Alanje donde la cultura material remite a la que caracteriza a los célticos (Pavón 1996); La Tabla de la Cañas de Capilla, donde como en Castillejos II se ve una coexistencia entre tradiciones meseteñas y meridionales (Domínguez de la

10 Los escasos datos habría que extrapolarlos de territorio limítrofes como el Campo de Zafra donde se ha propuesto una organización en asentamientos relativamente autónomos situados en Ilano (Pavón et alii., 2015) 
Concha y García Blanco 1991); y Sisapo, en Almodóvar del Campo, donde el hábitat pudo contraerse o ser inexistente en cronologías inmediatamente anteriores a la conquista romana (Zarzalejos et alii 1994) y donde las construcciones defensivas documentadas parecen relacionarse con la fase romano-republicana (Zarzalejos y Esteban 2007). Los datos de los célticos son algo más conocidos, especialmente gracias a los trabajos de Berrocal-Rangel (1992), aunque nuevamente las excavaciones son muy escasas en la zona, siendo el yacimiento de referencia el Castrejón de Capote en Higuera la Real (Badajoz).

El asentamiento-tipo es el castro, al menos en el sector céltico y se define por buscar ubicaciones en altura y fácilmente defendibles, situarse en las inmediaciones de cursos de agua menores y, habitualmente, completar la defensa natural de su emplazamiento con murallas. Pese a que durante mucho tiempo se sostuvo que antes de la conquista romana parte de ellos llegaron a convertirse en auténticos oppida ${ }^{11}$ (Berrocal-Ranger 1992), los datos actuales invitan a pensar a que estos enclaves centrales se fundaron y desarrollaron tras la conquista (Rodríguez Díaz y Enríquez Navascués 2001: 309), como está bien documentado en los sitios republicanos de Nertobriga (Berrocal-Rangel et alii 2017), Miróbriga (Pastor et alii 1992) y Hornachuelos (Rodríguez Díaz y Enríquez Navascués 2001: 305), o los augusteos de Contributa (Mateos y Pizzo 2014) y Arucci (Campos y Bermejo 2013). Por tanto, entre los celtolusitanos del espacio definido entre el Guadiana y Sierra Morena Occidental no hay muestras de la emergencia de asentamientos

11 Los oppida son considerados los centros rectores en la Europa céltica (Fernández-Götz 2013). tipo oppidum en momentos prerromanos, salvo, quizás, aquellos situados en la ribera del Guadiana como El Tamborrío o la Alcazaba de Badajoz. Sin embargo, las fuentes, como Apiano, sí que hablan de ciudades dentro de este espacio, lo que puede explicarse como la percepción romana de los asentamientos más destacados o incluso un intento de engrandecer las acciones bélicas desarrolladas. Por otro lado, no debemos olvidar que pese a su prácticamente nulo conocimiento, la gran mayoría de la población debió ocupar pequeños asentamientos de tipo aldeano en llano y sin defensas similares a El Espadañar.

Socialmente se ha defendido una mayor isonomía que durante la I Edad del Hierro (Berrocal-Rangel 1992: 284) y, de hecho, parece posible extrapolar en cierta medida los datos conocidos en otros territorios célticos que hablan de una estructura social trapezoidal más que piramidal (FernándezGötz 2014: 57), lo que contrastaría con la estructura socio-política característica de la fase anterior en la que la gran parte de la sociedad estaba supeditada a un muy reducido grupo de personas que se hallaba a una considerable distancia social. Esta mayor igualdad no implica sin embargo la ausencia de clases sociales con un acceso diferenciado a los recursos, como se puede ver en, por ejemplo, las referencias a un grupo social despojado de tierras (Sayas 1988) o el empleo de un armamento diferenciado (Diodoro 5, 33-34; Estrabón 3, 3, 6-7; 4, 15).

Antes de analizar desde el punto de vista de las fuentes a esta sociedad de frontera, como la definió García Moreno (1989), conviene repasar brevemente algunos de los topoi sobre estas gentes que ocupaban los territorios ribereños del Guadiana más allá 
de Sierra Morena Occidental. Sin ahondar en exceso podemos afirmar que la tradicional visión primitivista de estas gentes, que (mal) viven en tierras pobres y mal distribuidas y se ven obligados al bandolerismo para poder sobrevivir (Diodoro 5, 34, 6-7; Apiano Iber., 59) ha quedado superada por la investigación (Sánchez Moreno 2006). Muchas de las acciones tradicionalmente calificadas como razias han cobrado nueva luz a partir de una comprensión más profunda de esta sociedad y una visión más crítica de las fuentes. Así, los salteadores de caminos y ladrones de ganado que realizaban incursiones en territorios controlados por Roma o sus aliados se entienden mejor si se relacionan sus movimientos con el desplazamiento de su propio ganado en busca de pastos (Sánchez-Corriendo 1997; Sánchez Moreno 2006), aunque no siempre la presencia de contingentes de celto-lusitanos armados al Sur de Sierra Morena respondería, antes de Período de los Caudillos, a esta situación y se ha planteado la existencia de pactos militares con determinadas ciudades meridionales como Hasta Regia (García Moreno 1989: 88; Pérez Vilatela 2000: 130, 236-238; Sánchez Moreno 2017). El factor ganadero es fundamental para comprender a esta sociedad, no solamente porque la base de la diferenciación social entre los celto-lusitanos debió ser la posesión de estos recursos (Sánchez Moreno 2001: 156; 2006: 62-63), bienes que eran susceptibles de ser centralizados (Johnson y Earle 2003: 268), sino porque ganadería y guerra se encuentran estrechamente unidos y es común el adiestramiento bélico entre los grupos ganaderos (Johnson y Earle 2003: 274).

Tampoco parece que la explicación del ver sacrum (rito de paso) sea lo suficiente- mente satisfactoria para explicar los conflictos que asolan el Suroeste peninsular durante un siglo (Sánchez Moreno 2006: 63-64). Ello no implica que dicha práctica no pudiera existir, sino que las causas del enfrentamiento de Roma con los celto-lusitanos serían de otra índole.

En contra del tradicional primitivismo podemos apuntar algunas cuestiones más, como el extenso conocimiento que demuestran de la diplomacia internacional al tratar con púnicos y romanos (Sánchez Moreno y García Riaza 2012). De ello tenemos varios ejemplos, como los tratados firmados con los gobernadores romanos Atilio, Galba 0 Serviliano. Pero estos acuerdos no debieron ceñirse exclusivamente al mundo romano, su conocimiento de la diplomacia con Estados imperialistas debía retrotraerse a los distintos acuerdos con los cartagineses (Ciprés 1993:75-76; Sánchez Moreno y García Riaza 2012; Paniego 2013), e, incluso, se ha vinculado la acción Cauceno dentro del conflicto númida-cartaginés (Ciprés 1993: 76-77 y 154-155; Paniego 2013; Sánchez Moreno 2017).

Un último elemento que merece la pena señalar es la existencia de una institución que debió unir a parte de estas poblaciones con independencia de la etnia o las relaciones de parentesco: la devotio. Su exponente más claro son los juegos gladiatorios que se desarrollaron durante los festejos fúnebres de Viriato (Diodoro 31, 21; Apiano Iber., 75). Los lazos que unían a estos miembros de la sociedad con su líder tenían un carácter claramente fuera del parentesco y, que además de hablarnos de la existencia de unas posiciones sociales que no estarían relacionadas con el parentesco nos indican la existencia 
de un cuerpo armado que estaría unido a su líder de forma individual, un ejército privado fiel hasta la muerte, y aún después de ella, como demostrarían los juegos gladiatorios.

En resumen, nos encontramos con una sociedad bastante alejada de los estereotipos que la catalogaban como arcaica, pobre y agresiva, siendo en realidad mucho más sofisticada, profundamente conocedora del mundo que les rodea y con el que saben interactuar mucho más allá del enfrentamiento armado. Desgraciadamente, el conocimiento interno de esta sociedad es prácticamente nulo, y solamente podemos inferirlo a partir de las escasas informaciones de las fuentes y los aún insuficientes resultados arqueológicos.

Centrándonos en los datos de los autores clásicos que podrían señalar la existencia de un estado, hemos de resaltar que se ciñen a un momento muy concreto: la guerra contra Roma durante el generalato de Viriato. No es este el lugar para desarrollar los pormenores de la guerra, aunque sí conviene resaltar algunos elementos que, creemos, son importantes para comprender el generalato de Viriato y sus características. Por un lado, sus tropas debían tener una procedencia étnica variada, pese a que los romanos los englobaban en un etnónimo como es el de "Iusitano". Sin ir más lejos, Viriato contaba con el apoyo y la adhesión de varias ciudades que podríamos identificar como turdetanas y que se situaban en el valle del Guadalquivir. Por otro lado, pese a la enorme heterogeneidad de su ejército, no hay noticias sobre deserciones y traiciones, salvo, claro está, la que supuso el asesinato del Caudillo y el suceso de Cónnoba, si éste formaba parte de su ejército. Finalmente, este conglomerado de hombres mostraba un buen adiestramiento militar y una disciplina y conocimiento de la táctica fuera de toda duda y con una gran versatilidad que le permitía luchar en línea cerada, tender emboscadas y desarrollar su táctica más destacada, la concursare, que implica cuanto menos un alto grado de coordinación. Por todo ello, nos encontramos ante un auténtico ejército y no unas bandas 0 un conglomerado indefinido e informe de guerreros. Este ejército se dividiría en unidades menores con funciones específicas, como las tropas de guarnición en determinadas ciudades (Apiano Iber., 68). Incluso cabe la posibilidad que bajo el mando único de Viriato se encontrasen los ejércitos de Cónnoba, Curio y Apuleyo (Apiano Iber., 68-69), lo que nos hablaría de una compleja estructura interna.

El ejemplo de Galia nos muestra la existencia de una estructura intermedia entre el clan y la etnia, la subetnia o pagus (Fernández-Götz 2014: 59-61), cuya federación daría lugar a las etnias o civitates. Obviamente, esta situación no necesariamente es extrapolable, aunque podemos ver ciertos paralelismos. Así, parece que el ejército de Viriato estaría compuesto por varios pagi unidos militarmente, en una suerte de confederación cuyo origen sería una respuesta al imperialismo púnico y romano pese a que puedan rastrearse factores endógenos (Sánchez Moreno 2006: 67-68; Sánchez Moreno y García Riaza 2012: 1253; Pérez Rubio et alii 2013: 684). Esta confederación puede tratarse del último paso de una jefatura centralizada en el difuso y más que difícilmente discernible umbral que separa el Estado de la Jefatura compleja, como sucedió con los Ashanti, donde el origen del estado está en una confederación militar (Service 1984: 152-153), y en el de los zulúes, donde la 
unificación política de diversos grupos (en este caso podríamos asimilarlos a los pagi) se debió a la presión externa (Service 1984: 132). De esta forma, el Estado resultante no respondería al patrón de la ciudad-Estado, sino al del Estado étnico (Fernández-Götz 2014: 72-74, 170-174). Así, vemos como lo que en las fuentes aparece como una mera coalición militar podría estar reflejando una estructura social más compleja, articulada en torno a una serie de personajes que ostentaban un tipo de magistratura concreta. Desde luego es problemático el término con el que son llamados estos líderes indígenas, ya que actualmente su significado exacto sigue sin ser claro, aunque parece que estos caudillos lusitanos de mediados del siglo II a.C. reciben denominaciones que dan la idea de categorías superiores a simples magistraturas temporales, si bien con un "rango" inferior al que los textos clásicos otorgan a los ibéricoturdetanos (Sánchez Moreno 2002; Moret 2002-2003). El modo de alcanzar dicha magistratura parece ser la elección, como muestra el caso de Viriato (Apiano Iber., 62). Aunque las fuentes se centran en su componente militar, el ámbito de acción de estos mandatarios sería más amplio y alcanzaría esferas como la economía o las relaciones diplomáticas, en una sociedad que parece estaba ya muy regulada (Sánchez Moreno 2002; 2006; Salinas 2008).

Sobre esta magistratura que se observa a mediados del siglo II a.C. entre los celtolusitanos cabe preguntarse si solo se daba en tiempos de guerra, ya que las figuras de Púnico, Césaro o Viriato solo salen a relucir en las fuentes en su calidad de líderes militares. Los ejemplos de la Galia apuntan a que según el desarrollo de cada civitas esta magistratura podía surgir solo en tiempos de guerra 0 en las más avanzadas también en las de paz (Fernández-Götz 2014: 69). Podemos plantear que al menos para el caso de Viriato su posición en la estructura política no se vio alterada durante la paz, ya que el acuerdo del año 140 a.C. le nombra a él como representante político de los celto-lusitanos, aunque esto pudo deberse a su calidad de máximo exponente militar. Por el contrario, el hecho de que en el año 139 a.C. sea el encargado de dirigir las acciones diplomáticas y que su muerte origine el colapso del sistema, reincidirían en la continuidad de la magistratura en tiempos de paz, al menos en el caso de Viriato. Sobre ella, la mejor conocida, pocos datos hay del alcance y su naturaleza, aunque su figura parece ser la de un rey imbuido de rasgos púnico-helenísticos, al menos en el cenit de su poder y desde la perspectiva de los autores clásicos (García Quintela 1993; Lens 1994; Sánchez Moreno y García Riaza 2012: 1256). Esta visión subjetiva de los autores clásicos, sin embargo, parece bastante cercana a la realidad en varios aspectos. Viriato es, como hemos señalado, sin duda un elemento coordinador insustituible, un jefe fuertemente asentado en su poder (López Melero 1988) que basa este en la guerra, aunque sus funciones excederían el ámbito militar, y en su función como redistribuidor de bienes (Sánchez Moreno 2001; 2002), retroalimentándose positivamente ambas vertientes.

Esta magistratura fuertemente asentada e indiscutiblemente personalizada en la figura de Viriato se inserta en una estructura político-social que si no se encuentra en la estatalidad sí está en sus albores como defiende López Melero (1988: 259) cuando califica el gobierno de Viriato como el germen de un regnum. El ejemplo de los zulúes 


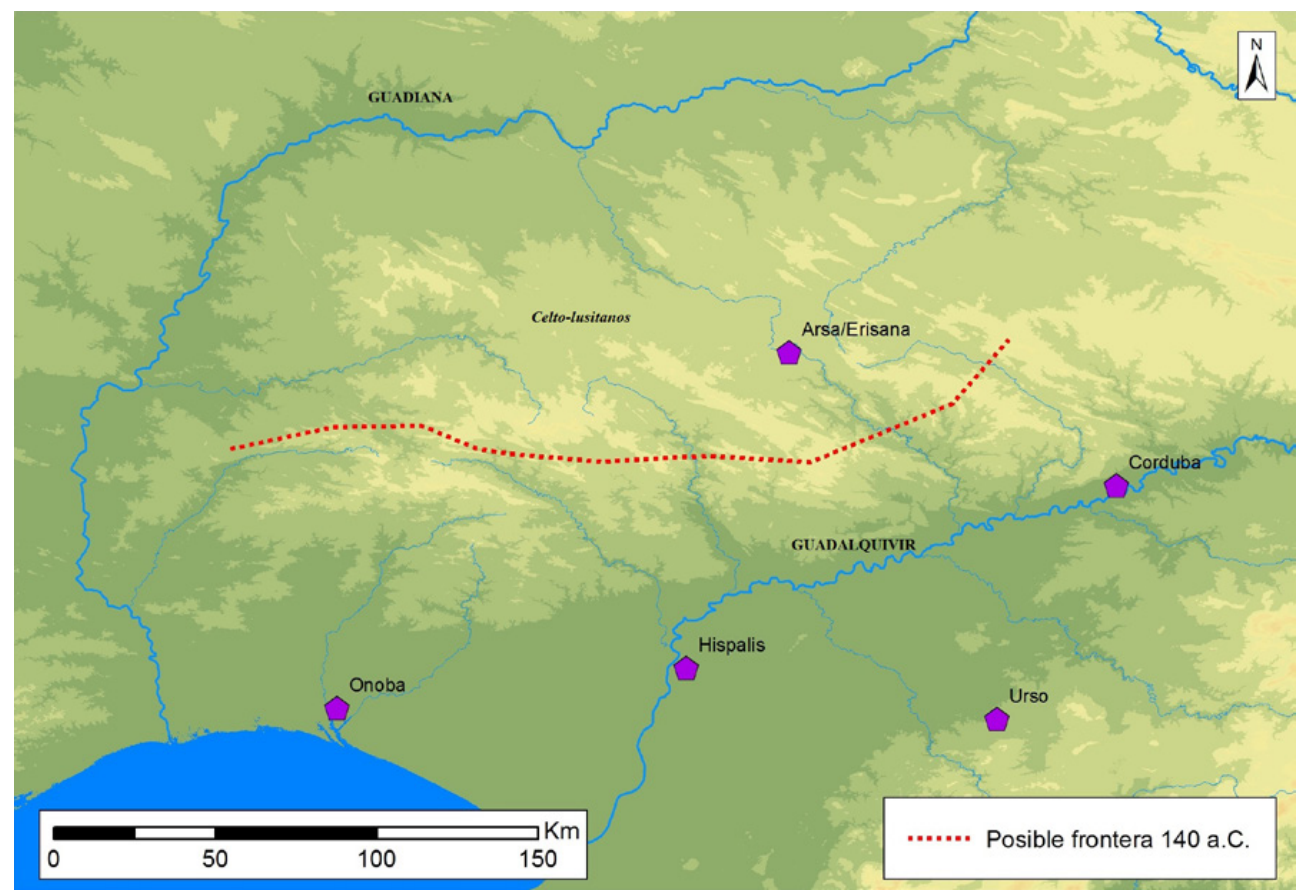

Fig. 2. Posible frontera en el 140 a.C.

apunta a esta hipótesis, ya que si el origen del Estado está en los éxitos militares de Shaka, la emergencia del verdadero Estado debe buscarse en las políticas de sus sucesores que implicaban una serie de cambios lentos y graduales en varios aspectos de la ordenación social (Service 1984: 137). Sánchez Moreno (2006: 68) enumera una serie de puntos a favor de la existencia de un Estado: embajadas, delegaciones y guarniciones; infraestructura de comunicaciones; diplomacia; ejército; política tributaria; e, incluso, una suerte de funeral de Estado.

La existencia de un Estado en vías de formación o de consolidación también ha sido argumentado como la causa del ataque sin provocación llevado a cabo por el magistrado romano de la Ulterior en el año 139
a.C., ya que Roma no vería con buenos ojos el desarrollo de una estructura política de tales características en su limes (García Riaza 2002: 156)

Las fuentes grecolatinas no son explícitas a la hora de hablar de la existencia de un Estado en la frontera occidental de la Península Ibérica (Fig. 2), aunque el pacto del año 140 a.C. sugiere que así era percibido por el Estado romano. En él Viriato fue situado a la altura de reyes aliados como Hieron II de Siracusa y llamado amicus populi romani, además se le concedía autonomía política sobre su territorio (el espacio situado entre el Guadiana y Sierra Morena Occidental), en un acuerdo paritario entre ambos actores políticos (García Riaza 2002: 153). Se ha sugerido que este acuerdo tendría una lec- 
tura en clave interna en la sociedad celtolusitana pues en él ganaba la titulación real que podía legitimarle en su territorio (Salinas 2008: 109-110). Más clara es la cita de Floro $(1,33,15)$ cuando se refiere a Viriato como el Rómulo de Hispania.

Si atendemos a los indicadores objetivos para definir la existencia de un Estado, podemos observar como gran parte de ellos se cumplen. Así, todo indica que la población sí era suficiente para realizar una categorización y que existiera una estratificación y especialización. Incluso debió haber una relativa alta densidad de población, requisito citado por Johnson y Earle (2007: 340). Al menos a ello apuntan las cifras de combatientes, aunque el registro arqueológico se muestra parco en este aspecto, quizá porque como hemos señalado previamente gran parte de la población debió habitar en asentamientos de escasa entidad y difícilmente localizables como el de El Espadañar. Tanto la documentación de distintos tipos de hábitat como las citas literarias inciden en la existencia de diferentes grupos sociales. La ciudadanía, marcada por la residencia y no por el nacimiento es otro elemento difícilmente rastreable, aunque como se ha señalado la presencia dentro del territorio controlado por Viriato de diferentes unidades étnicas podrían indicar un desarrollo en dicho sentido. Incluso la existencia de diferentes grupos étnicos y la ausencia de parentesco entre las élites y los gobernados abundan a favor de la existencia de un Estado (Johnson y Earle 2007: 315). Más claro y fácilmente defendible sería el gobierno centralizado, en este caso en la persona del caudillo, que contaría con un cuerpo de guardia personal. Se han vinculado los sacrificios de guerreros para honrar a Viriato tras su muerte con la institución de la devotio, lo que indi- caría una relación personal de los guerreros con el caudillo. Este tipo de relación, que podríamos calificar como individual y privada, es propia de las jefaturas, frente a la institución altamente estructurada no unida por lazos personales de los ejércitos estatales (Johnson y Earle 2003: 269). No obstante, ambas realidades bien pudieron darse en el mismo momento, así Viriato contaría con una guardia personal unida a él individualmente, que coexistiría con un ejército regular (Ciprés 1993: 154-155), como indica la existencia de diferentes cuerpos, divisiones y existencia de guarniciones. Asimismo, es interesante recordar que la guerra de Viriato era de carácter hegemónico (Ciprés 1993: 154-155) y salvo en ocasiones puntuales o los momentos finales de carácter ofensivo, lo que implicaría un auténtico ejército con capacidad logística, cadena de mando, etc. Sobre el monopolio de la fuerza, la posible existencia de ejércitos privados en otros personajes indicaría la inexistencia del monopolio completo de la violencia, aunque ello no invalida la existencia de un Estado, siendo un ejemplo paradigmático la Roma republicana (Motta y Terrenato 2006). Finalmente, pocos datos se pueden apuntar sobre una posible ideología común que, por otra parte, debido a lo efímero del sistema no debió llegar a concretarse plenamente.

Si se utilizan los criterios de Childe, más materiales, vemos que gran parte de los requisitos están ausentes, como el urbanismo, ya que parece que las ciudades meridionales del bando de Viriato durante gran parte del conflicto no llegaron a formar parte del territorio reconocido tras el pacto con Roma y tampoco debieron ser nunca centros políticos de primer orden sobre otras estructuras político-organizativas dentro de la organización 
territorial. Aunque la ausencia de ciudades tampoco es un elemento definidor para negar la existencia de un Estado, pues no es ella la que genera este sistema político (Service 1987: 304-305). Además, en los estados étnicos el papel de la ciudad es secundario y posterior al origen del sistema (FernándezGötz 2014: 73-74). Tampoco hay muestras en la cuenca media del Guadiana de la existencia de escritura o moneda ${ }^{12}$, se desconoce el desarrollo de las ciencias y los únicos edificios públicos monumentales conocidos son las murallas y elementos defensivos, en las cuales, no obstante, se ha valorado su función como elemento cohesionador del grupo (Berrocal-Rangel 2004).

De esta forma vemos que hay suficientes argumentos para plantear la existencia de un estado frustrado, o cuanto menos el germen de éste. Su origen se remontaría a las magistraturas de los llamados caudillos celto-lusitanos. La figura de Viriato supone un paso adelante en la maduración y consolidación de este sistema incipiente que, no obstante, fue finalmente abortado por la muerte de Viriato y la conquista romana del territorio.

Este estado sería secundario de primera generación, formado al borde de sociedades complejas más maduras del que las élites tomarían prestados determinados elementos simbólicos y materiales (Parkinson y Galaty 2007: 115-116). En el caso de Viriato, por

12 La aparición de la moneda, centrada en la Beturia oriental, sería coetánea a la conquista romana y no anterior a ésta, posiblemente vinculada con la presencia de poblaciones de origen norteafricano aliadas de Roma.

13 En este aspecto hemos de ser cautos, pues no debemos olvidar que las informaciones provienen de autores grecolatinos que bien pudieron buscar elementos conocidos en los atributos de la magistratura de Viriato. ejemplo, se ha reincidido en los rasgos púnico-helenísticos de su magistratura ${ }^{13}$.

Claramente en contra de esta perspectiva se sitúa Blázquez (1987), quien afirma que Viriato, cuyo poder se basaba exclusivamente en el ejército, no tuvo la altura política de otros líderes para crear un estado y tampoco parece que fuera ese su objetivo. En esta línea también se posiciona Muñiz Coello (1994), para quien la sociedad lusitana es claramente pobre y atrasada y en la cual no se daban las premisas necesarias para que existiera alguna institución asimilable al concepto de regulus. La jefatura de Viriato, según este investigador, se ceñiría exclusivamente a su facción tribal. Berrocal-Rangel (1992: 284; 1995: 123) tampoco cree que la sociedad celto-lusitana de mediados del siglo II a.C. lograse superar el umbral del Estado y considera que las jefaturas que se desarrollaban se basaban en el ejército y no en el control económico, interpretación similar a la defendida por Almagro (2014: 194), quien pese a valorar su capacidad para organizar a miles de combatientes y dominar ciudades y amplios territorios no cree que se alcanzase una sociedad estatal, aunque se hallaría a las puertas de ésta.

En definitiva, el mayor obstáculo existente para considerar la emergencia de un Estado en las fronteras romanas en el Suroeste de la Península Ibérica a mediados del siglo II a.C. es la brevedad de éste, pues como habíamos señalado antes, la continuidad temporal del sistema es importante. Probablemente estuvieran sentadas todas las bases para que apareciese un sistema político de tipo estatal pero la intervención romana evitó que pudiera cristalizar, dando lugar a un estado frustrado, cuyo origen, catalizador y fin 
estuvo en la presencia de culturas estatales en sus inmediaciones, primero los cartagineses y final y fundamentalmente los romanos.

\section{CONCLUSIONES}

Durante la Edad del Hierro se desarrollaron en la cuenca media del Guadiana diferentes sistemas políticos que en ciertos casos han sido considerados como estatales. La dificultad para discernir las jefaturas avanzadas de los estados así como las limitaciones del registro material y las fuentes grecolatinas para identificar tipos de organización política complican la definición de estas sociedades transicionales, ya que el umbral de la estatalidad es ancho y difuso.

Si atendemos a los datos conocidos durante el Hierro Antiguo podemos ver que existían todos los prerrequisitos necesarios para que emergiese una sociedad estatal. A pesar de que desconocemos el auténtico funcionamiento interno de esta sociedad y los datos son muy parciales, creemos que es posible afirmar la existencia de un Estado en la primera fase del Hierro I. Como es habitual en sociedades de transición, la existencia de resistencias debió provocar situaciones de dualismo, donde este estado incipiente coexistiría con jefaturas avanzadas en sus fronteras, creando una tensión entre ambos modelos.

La existencia de dicho estado debió ser efímera y posiblemente las resistencias sociales y la falta de madurez del nuevo sistema político permitió que se revirtieran, al menos parcialmente, los cambios que habían posibilitado el desarrollo de una estructura estatal. De esta forma, a finales del Hierro I, coincidiendo con el desarrollo y esplendor de los edificios aristocráticos que jalonan el Guadiana Medio, parece que nos encontramos nuevamente ante una sociedad de jefatura que, sin embargo, debió conservar algunos de los rasgos propios de la sociedad estatal que la había precedido, lo que hace más complicado todavía discernir la estructura política que regía dicha sociedad. El rasgo más característico de este momento es la disgregación del poder en pequeños centros, siendo ésta la causa principal de las que podemos inferir la ausencia de un estado.

Finalmente, el sistema de la I Edad del Hierro terminaría colapsando definitivamente hacia el 400 a.C., desconociéndose si fue a consecuencia de causas internas o externas. Este cambio de modelo significó la aparición de un nuevo sistema político, social y económico que supuso una ruptura importante respecto al precedente y que parece que aleja a las poblaciones asentadas entre el Guadiana y Sierra Morena Occidental durante los siglo IV y III a.C. del modelo estatal.

No obstante, y posiblemente debido a la presión de cartagineses y romanos, se observa un proceso de evolución política y centralización en el siglo II a.C. que tendría su cenit en el generalato de Viriato, quien en el 140 a.C., en el culmen de su poder, debió ser la cabeza de un sistema que si no se puede catalogar de estatal sí cumpliría todas las exigencias de este. La estructura definida durante el gobierno de Viriato estaba sustentada en unas bases muy distintas a las que habían sido los pilares sobre los que se construyó el sistema político de la I Edad del Hierro y debido a su origen, que se ha de buscar en la existencia de señores de la guerra que paulatinamente debieron aumentar y perpetuar su poder, atribuciones y posición, así como la distancia temporal y el hiato exis- 
tente nos permite afirmar que su origen no estuvo relacionado con las experiencias previas de la I Edad del Hierro.

La muerte del caudillo celto-lusitano y la inmediata conquista del territorio por Roma puede considerarse la causa que impidió cristalizar a este modelo de organización sociopolítica que se encontraba en los límites de la estatalidad.

En definitiva, vemos como hay tres momentos durante la Edad del Hierro en el Guadiana Medio en el que se pudo alcanzar el rango de la estatalidad. La experiencia más cercana al desarrollo de un estado fue la liderada por los centros urbanos de la ribera del Guadiana a principios del Hierro Antiguo. No obstante, la fragilidad del sistema desarrollado debió conducir a una reestructuración del poder en este territorio a finales del Hierro I en el que las formas estatales parece que pudieron conservarse, no así el fondo, donde la dispersión del poder nos permite vislumbrar un retorno a un modelo de jefatura avanzada. Sin aparentemente ninguna relación con estas experiencias, en un marco histórico completamente distinto y emergiendo a partir de unas premisas totalmente diferentes, profundamente influido por la vecindad de sociedades estatales muy desarrolladas y estructuradas, tenemos el caso de los celto-lusitanos bajo el gobierno de Viriato. La brevedad de dicha experiencia así como la ausencia de una continuidad debido a causas exógenas nos incapacita para afirmar rotundamente la aparición de un estado, aunque posiblemente nos encontramos ante una situación similar a la los zulúes bajo el mandato de Shaka.

\section{BIBLIOGRAFÍA}

ALCINA FRANCH, J. (1986): "El concepto de "jefatura" en el contexto de la evolución social", Arbor, 123-482, 35-54.

ALMAGRO GORBEA, M. (2008): "Demografía y sociedad" en ALMAGRO GORBEA, M. (dir.) La necrópolis de Medellín, Real Academia de la Historia, Madrid, 907-1003.

- (2014): "Los Lusitanos" en ALMAGRO GORBEA, M. (ed.) Protohistoria de la Península Ibérica: del Neolítico a la Romanización, Universidad de Burgos y Fundación Atapuerca, Burgos, 183194.

ALMAGRO GORBEA, M.; LORRIO ALVARADO, A.; MEDEROS MARTÍN, A.; TORRES ORTIZ, M. (2008a): "Medellín y su territorio como ciudadestado" en ALMAGRO GORBEA, M. (dir.) La necrópolis de Medellín, Real Academia de la Historia, Madrid, 1019-1032. (2008b): "La ciudad-estado de Medellín-Conisturgis y la cuenca del Guadiana en el periodo orientalizante" en ALMAGRO GORBEA, M. (dir.) La necrópolis de Medellín, Real Academia de la Historia, Madrid, 1033-1059.

(2008c): "El territorio de Medellín en los siglos VI-V a.C." en JIMÉNEZ ÁVILA, J. (coord.) Sidereum Ana I. El río Guadiana en época postorientalizante, CSIC, Mérida, 149-176.

BERROCAL-RANGEL, L. (1992) Los pueblos célticos del Suroeste de la Península Ibérica, Complutum Extra, Madrid.

(1995): “Etnogénesis y territorio: jefaturas, estatalización y moneda entre los pueblos betúricos" en GARCÍA-BELLIDO GARCÍA DE DIEGO, M. P.; SOBRAL CENTENO, R. M. (coord.) La moneda hispánica: ciudad y territorio. Actas del I encuentro peninsular de numismática antigua: 117-128. 
- (1998): La Baeturia. Un territorio prerromano en la baja Extremadura, Diputación de Badajoz, Badajoz.

(2004): "La defensa de la comunidad: sobre las funciones emblemáticas de las murallas protohistóricas en la Península Ibérica", Gladius, 24, 27-98.

BERROCAL-RANGEL, L.; BARRERA ANTÓN, J. L. de la; CASO AMADOR, R. (2017): Nertobriga Concordia Iulia. Del oppidum céltico al municipium romano, Universidad de Alicante, Alicante.

BLÁZQUEZ MARTÍNEZ, J. M. (1987): "El Estado de Burebista y los pueblos de la Península Ibérica en época helenística", Gerión, 5, 195-210.

CAMPOS CARRASCO, J. M.;BERMEJO MELÉNDEZ, J. (2013): "Arucci y Turobriga: su problemática y reducción", AEspA, 86, 113-130.

CARNEIRO, R. L. (1970): "A Theory of the Origin of the State", Science, 169, 733-738.

CELESTINO PÉREZ, S. (2011-2012) "Arqueología protohistórica de La Serena", CUPAUAM, 3738, 297-305.

CELESTINO PÉREZ, S.; RODRÍGUEZ GONZÁLEZ, E. (2017): "De lo invisible a lo visible. La transición entre el Bronce Final y la Primera Edad del Hierro en el valle medio del Guadiana" en CELESTINO PÉREZ, S. y RODRÍGUEZ GONZÁLEZ, E. (coord.) Territorios comparados: los valles del Guadalquivir, el Guadiana y el Tajo en época tartésica, CSIC, Mérida, 183-212.

CHAMORRO CALZÓN, J. (1991): El materialismo cultural y el origen del Estado, Universidad Autónoma de Madrid. Inéd.

CHILDE, V. G. (1972): Qué sucedió en la historia, La Pléyade, Buenos Aires.

CIPRÉS TORRES, P. (1993): Guerra y sociedad en la Hispania Indoeuropea, Universidad del País Vasco, Vitoria-Gasteiz.

CLAESSEN, H. J. M.; SKALNÍK, P. (1978): "The Early State: Theories and Hypotheses" en CLAES-
SEN, H. J. M.; SKALNÍK, P. (ed.) The Early State, Mouton, The Hague, 3-29.

CLASTRES, P. (2014a): "Intercambio y poder: fiIosofía de la jefatura india", en La sociedad contra el Estado, Virus, Barcelona, 37-57.

- (2014b): "La sociedad contra el Estado", en La sociedad contra el Estado, Virus, Barcelona, 201-230.

DOMÍNGUEZ DE LA CONCHA, M. C. y GARCÍA BLANCO, J. (1991): "La Tabla de las Cañas (CapiIla, Badajoz). Apuntes preliminares", Extremadura Arqueológica, 2, 235-245.

ENGELS, F. (1977): El origen de la familia, la propiedad privada y el Estado, Fundamentos, Madrid.

FERNÁNDEZ GÖTZ, M. A. (2013): "Una nueva mirada sobre los Oppida de la Europa Templada", Complutum, 24-1, 131-150.

- (2014): De la familia a la etnia. Protohistoria de la Galia Oriental, Real Academia de la Historia, Madrid.

_ (2017): "Contested Power: Iron Age Societies Against the State?" en HANSEN, S.; MÜLLER, J. (ed.) Rebellion and Inequality in Archaeology, Habelt, Bonn, 271-286.

FRIED, M. H. (1978): "The State, the Chiken, and the Egg; 0, What Came First?" en COHEN, R.; SERVICE, E. R. (ed.) Origins of the State. Institute for the Study of Human Issues, Philadelphia, 35-47.

(1979): "Sobre la evolución de la estratificación y del Estado" en LLOBERA, J. R. Antropología Política, Anagrama, Barcelona, 133-151.

GARCÍA MORENO, L. A. (1989): "Hispaniae Tumultus. Rebelión y violencia indígena en la España romana de época republicana", Polis, 1, 81-107.

GARCÍA QUINTELA, V. M. (1993): "Viriato y la ideología trifuncional europea”, Polis, 5, 111138. 
GARCÍA RIAZA, E. (2002): Celtíberos y lusitanos frente a Roma: diplomacia y derecho de guerra, Anejos de Veleia, Vitoria-Gasteiz.

HARRIS, M. (1982): El materialismo cultural, Alianza, Madrid.

(1993): Jefes, cabecillas y abusones, Alianza, Madrid.

JIMÉNEZ ÁVILA, J. (2001): "Los complejos monumentales post-orientalizantes del Guadiana y su integración en el panorama del Hierro antiguo del suroeste peninsular" en RUIZ MATA, A.; CELESTINO PÉREZ, S. (coord.) Arquitectura oriental y orientalizante en la Península Ibérica, CSIC, Madrid, 193-226.

- (2005): "Cancho Roano: el proceso de privatización de un espacio ideológico", Trabajos de Prehistoria, 62-2, 105-124.

- (2016): "El Post-orientalizante, entre España y Portugal; entre lo Tartésico y lo Turdetano", Cadernos do Museu da Lucerna, 2, 37-60.

JIMÉNEZ ÁVILA, J.; ORTEGA BLANCO, J. (2008): "El poblamiento en Ilano del Guadiana Medio durante época post-orientalizante" en JIMÉNEZ ÁVILA, J. (coord.) Sidereum Ana I. El río Guadiana en época post-orientalizante, CSIC, Mérida, 251282.

JOHNSON, A. W.; EARLE, T. (2003): La evolución de las sociedades desde los grupos cazadores-recolectores al estado agrario, Ariel, Barcelona.

KRISTIANSEN, K.; LARSSON, T. B. (2006): La emergencia de la sociedad del Bronce: viajes, transmisiones y transformaciones, Bellaterra, Barcelona.

KURTZ, G. (2003): "Los hierros de Cancho Roano" en CELESTINo PÉREZ, S. (ed.) Cancho Roano VIII. Los materiales arqueológicos I, Junta de Extremadura, Mérida, 293-364.

LENS TUERO, J. (1994): "Viriato, héroe y rey cínico" en LENS TUERO, J. (coord.) Estudios sobre Diodoro de Sicilia, Universidad de Granada, Granada, 127-143.
LEWELLEN, T. C. (2009): Introducción a la Antropología Política, Bellaterra, Barcelona.

LÓPEZ MELERO, R. (1988): "Viriatus Hispaniae Romulus", Espacio, Tiempo y Forma. Serie II. Historia antigua, 1, 247-262.

LULL, V.; RISCH, R. (1995): “El Estado argárico", Verdolay, 7: 97-109.

LULL, V.; MICÓ, R. (2007): Arqueología del origen del Estado: las teorías, Bellatera, Barcelona.

MARX, K.; ENGELS, F. (1977): "El manifiestos del Partido Comunista" en Marx y Engels. Obras escogidas en dos tomos, Progreso, Moscú: 20-51.

MATALOTO, R. (2008): "0 pós-orientalizante que nunca o foi: uma comunidade camponesa na Herdade da Sapatoa" en JIMÉNEZ ÁVILA, J. (coord.) Sidereum Ana I. El río Guadiana en época postorientalziante, CSIC, Mérida, 219-250.

MATEOS CRUZ, P.; PIZZO, A. (2014): "La basílica de Contributa Iulia (Medina de las Torres, Badajoz)", Zephyrus, 74, 181-201.

MENÉNDEZ MENÉNDEZ, A.; SANABRIA MURILLO, D.; SÁNCHEZ HIDALGO, F.; GIBELLO BRAVO, V. M.; JIMÉNEZ ÁVILA, J. (2013): “La necrópolis orientalizante de Valdelagrulla (MedeIlín, Badajoz). Datos preliminares", Actas del VI Encuentro de Arqueología del Suroeste peninsular, 999-1030.

MORET, P. (2002-2003): “Los monarcas ibéricos en Polibio y Tito Livio", CuPAUAM, 28-29, 23-34.

MOTTA, L.; TERRENATO, N. (2006): "The origins of the State par excellence. Power and society in Iron Age Rome", Bibracte, 12-4, 225-234.

MUÑIZ COELLO, J. (1994): “Monarquías y sistemas de poder entre los pueblos prerromanos de la Península Ibérica" en SÁEZ, P.; ORDÓÑEZ, S. (ed.) Homenaje al profesor Presedo, Universidad de Sevilla, Sevilla, 283-296.

PANIEGO DÍAZ, P. (2013): "La guerra en la Beturia céltica: del siglo $\mathrm{V}$ a.C. a la muerte de Viriato", Historia Autónoma, 2, 13-28. 
_ (2014): "Los túrdulos del occidente peninsular", Historia Autónoma, 5, 27-41.

(2017): "Cartago, Roma y las poblaciones de la Cuenca Media del Guadiana" en Formas, manifestaciones y estructuras del poder político en el Mundo Antiguo, Universidad Autónoma de Madrid, Madrid, 135-155.

PARKINSON, W. A.; GALATY M. L. (2007): "Secondary States in Perspective: An Integrated Approach to State Formation in the Prehistoric Aegean", American Anthropologist, 109-1, 113129.

PASTOR MUÑOZ, M.; PACHÓN ROMERO, J. A.; CARRASCO RUS, J. (1992) Excavaciones arqueológicas en el Cerro del Cabezo (Capilla, Badajoz). Campañas 1987-1988, Editorial Regional de Extremadura, Mérida.

PAVÓN SOLDEVILA, I. (1996): "El castro de "La Mesilla" (Alange, Badajoz). Apuntes para la definición de la Segunda Edad del Hierro en el valle del Matachel" en CuPAUAM, 23, 124-163.

PAVÓN SOLDEVILA, I.; DUQUE ESPINO, D. M.; RODRÍGUEZ DÍAZ, A. (2015): "Prehistoria y Antigüedad en el campo de Zafra: una perspectiva desde el estudio del poblamiento", Revista de Estudios Extremeños, 71-1, 67-114.

PÉREZ MACÍAS, J. A. (1996): "La transición a la Edad del Hierro en el Suroeste peninsular: el problema de los Celtici", SPAL, 5, 101-114.

PÉREZ RUBIO, A.; SÁNCHEZ MORENO, E.; PER GIMENO, L.; MARTÍNEZ MORCILLO, J. A.; GARCÍA RIAZA, E. (2013): "Symmachíai celtibéricas (220-133 a.C.): coaliciones militares en el horizonte del imperialismo mediterráneo", Palaeohispánica, 13, 675-697.

PÉREZ VILATELA, L. (2000): Lusitania. Historia y Etnología, Real Academia de la Historia, Madrid.

PRICE, B. J. (1978): "Secondary State Formation: an Explanatory Model" en COHEN, R.; SERVICE, E. R. (ed.), Origins of the State. Institute for the Study of Human Issues. Philadelphia, 161-185.
RODRÍGUEZ DÍAZ, A. (1987): El poblamiento prerromano en la Baja Extremadura, Universidad de Extremadura, Inéd.

(2009): Campesinos y señores del campo: tierra y poder en la protohistoria extremeña, Bellaterra, Barcelona.

RODRÍGUEZ DÍAZ, A.; ENRÍQUEZ NAVASCUÉS, J. J. (2001): Extremadura tartésica. Arqueología de un proceso periférico, Bellaterra, Barcelona.

RODRÍGUEZ DÍAZ, A.; PAVÓN SOLDEVILA, I.; DUQUE ESPINO, D. (2004): "La Mata y su territorio" en RODRÍGUEZ DÍAZ, A. (ed.), El edificio protohistórico de "La Mata" (Campanario, Badajoz) y su estudio territorial, Universidad de Extremadura, Cáceres, 497-569.

_ (2009): "Contexto territorial e histórico" en RODRÍGUEZ DÍAZ, A.; PAVÓN SOLDEVILA, I.; DUQUE ESPINO, D. (eds.), El caserío de Cerro Manzanillo (Villar de Rena, Badajoz) y la colonización agraria orientalizante en el Guadiana Medio, Junta de Extremadura, Mérida, 183-322.

_ (2011): "El poblado" en RODRÍGUEZ DÍAZ, A.; PAVÓN SOLDEVILA, I.; DUQUE E. (eds.), El poblado prerromano de Entrerríos (Villanueva de la Serena, Badajoz). Campaña de 2008, Junta de Extremadura, Mérida, 27-122.

RODRÍGUEZ GONZÁLEZ, E. (2016): El reflejo de Tartesos en la periferia del Guadiana. Universidad Autónoma de Madrid. Recuperado de: https://repositorio.uam.es/handle/10486/674741

RODRÍGUEZ GONZÁLEZ, E.; CELESTINO PÉREZ, S. (2017a): "El valle medio del Guadiana durante la I Edad del Hierro: una nueva lectura sobre su organización territorial" en CELESTINO PÉREZ, S.; RODRÍGUEZ GONZÁLEZ, E. (coord.) Territorios comparados: los valles del Guadalquivir, el Guadiana y el Tajo en época tartésica, CSIC, Mérida, 183-212.

(2017b) "Las estancias de los dioses: la habitación 100 del yacimiento de Casas del Turuñuelo (Guareña, Badajoz)", CUPAUAM, 43, 179194. 
ROVIRA LLORENS, S.; MONTERO RUIZ, S.; ORTEGA BLANCO, J.; JIMÉNEZ ÁVILA, J. (2005): "Bronce y trabajo del bronce en el poblado orientalizante de "El Palomar (Oliva de Mérida, Badajoz)" en CELESTINO PÉREZ, S.; JIMÉNEZ ÁVILA, J. (ed.) El período Orientalizante, CSIC, Mérida, 1231-1240.

RUIZ RODRÍGUEZ, A.; MOLINOS MOLINOS, M. (1988): "Tribus y ciudades: planteamiento de un sistema de contradicciones en la estructura del Estado de los pueblos ibéricos del Sur de la Península Ibérica", Studia Historica. Historia Antigua, 6, 53-60.

SALINAS DE FRÍAS, M. (2008) "La jefatura de Viriato y las sociedades del occidente de la Península Ibérica", Palaeohispanica, 8, 89-120.

SANABRIA MURILLO, D. (2008) Paisajes rurales protohistóricos en el Guadiana Medio: "El Chaparral" (Aljucén, Badajoz), Junta de Extremadura, Mérida.

SANABRIA MURILLO, D.; SÁNCHEZ HIDALGO, F.; MENÉNDEZ MENÉNDEZ, A.; GIBELLO BRAVO, V. (2013): "Nuevos datos para el conocimiento de la Segunda Edad del Hierro en la Baeturia Túrdula. El yacimiento de El Espadañar (Quintana de la Serena, Badajoz)", VI Encuentro de Arqueología del Suroeste Peninsular, 1245-1273.

SÁNCHEZ MORENO, E. (2001): "Algunas notas sobre la guerra como estrategia de interacción social en la Hispania prerromana: Viriato, jefe redistributivo (I)", Habis, 32, 149-169.

_- (2002): "Algunas notas sobre la guerra como estrategia de interacción social en la Hispania prerromana: Viriato, jefe redistributivo (y II)", Habis, 33, 141-174.

- (2006): "Ex pastore latro, ex latrone dux... Medioambiente, guerra y poder en el occidente de Iberia" en ÑACO DEL HOYO, T.; ARRAYÁS MORALES, I. (eds.), War and territory in the Roman World, BAR, Oxford, 55-79.

(2017): "Imperialism and multipolarity in the Far West: beyond the Lusitanias (237-146 BC)", en ÑACO DEL HOYO, T.; LÓPEZ SÁNCHEZ,
F. (eds.), Warlords. War and Interstate relations in the Ancient Mediterranean 404 BC-AD 14, Brill, Leiden.

(e.p.): "Truco o trato? El reparto de tierras a los lusitanos, un opaco en la expansión romana en el Far West", en TORREGARAY PAGOLA, E. (ed.), Gestionar el fracaso, algunas sombras en la diplomacia romana, Universidad del País Vasco, Vitoria.

SÁNCHEZ MORENO, E.; GARCÍA RIAZA, E. (2012): "La interacción púnica en Iberia como precedente de la expansión romana: el caso de Lusitania" en COCCO, M. B., GAVINI, A.; IBBA, A. (ed.), L'Africa romana. Trasformazione dei paesaggi del potere nell'Africa settentrionale fino alla fine del mondo antico, Carocci, Roma, 1249-1260.

SÁNCHEZ-CORRIENDO JAÉN, J., (1997): “Bandidos lusitanos o pastores trashumantes? Apuntes para el estudio de la trashumancia en Hispania", Hispania Antiqua, 21, 69-92.

SAHLINS, M. D. (1977): Las sociedades tribales, Labor, Barcelona.

SAYAS ABENGOCHEA, J. J. (1988): "El bandolerismo lusitano y la falta de tierras", Espacio, Tiempo y Forma. Historia moderna, 1, 701-714.

SERVICE, E. R. (1984): Los orígenes del Estado y de la civilización. El proceso de la evolución cultural, Alianza, Madrid.

SEVILLANO PEREA, L. M.; MAYORAL HERRERA, V.; SALAS TOVAR, E.; LICERAS GARRIDO, R.; HERAS MORA, F. J. (2013): "Detectando prácticas agrarias antiguas en el territorio sur de Medellín. La expresión material de las actividades agrícolas protohistóricas del Suroeste peninsular", Actas VI Encuentro de Arqueología del Suroeste Peninsular, 1031-1064.

WAGNER, C. G. (1990): "La Jefatura como instrumento de análisis del historiador. Cuestiones teóricas y metodológicas", Espacio y Organización Social, 91-108.

WAGNER, C. G.; PLÁCIDO SUÁREZ, D.; ALVAR EZQUERRA, J. (1996): "Consideraciones sobre 
los procesos de estatalización en la Península Ibérica", Complutum Extra, 6-2, 139-150.

WALID SBEINATI, S.; NUÑO FONT, R. (2005): "Aplicaciones arqueogeográficas al estudio de las sociedades del período orientalizante: ¿Quién construyó Cancho Roano?" en CELESTINO PÉREZ, S.; JIMÉNEZ ÁVILA, J. (ed.), El período Orientalizante, CSIC, Mérida, 977-983.

WALID SBEINATI, S.; PULIDO ROYO, J. (2013): "El poblado fortificado de la Edad del Hierro del Cerro de Tamborrío (Entrerríos, Villanueva de la Serena, Badajoz)", Actas VI Encuentro de Arqueología del Suroeste Peninsular, 1179-1224.

WOLF, E. R. (2005): Europa y la gente sin historia, Fondo de Cultura Económica, México.
ZARZALEJOS PRIETO, M.; FERNÁNDEZ OCHOCA, C.; HEVIA GÓMEZ, P.; ESTEBAN BORRAJO, G. (1994): "Excavaciones en la Bienvenida (Ciudad Real). Hacia una definición preliminar del horizonte histórico-arqueológico de la Sisapo antigua", Jornadas de Arqueología de Ciudad Real en la Universidad Autónoma de Madrid, 167-194.

ZARZALEJOS PRIETO, M.; ESTEBAN BORRAJO, G. (2007): "La secuencia defensiva de La Bienvenida-Sisapo (Almodóvar del Campo, Ciudad Real). El flanco Suroriental de la fortificación" en BERROCAL-RANGEL, L.; MORET, P. (coord.), Paisajes fortificados de la Edad del Hierro: las murallas protohistóricas de la meseta y de la vertiente atlántica en su contexto europeo, Real Academia de la Historia, Madrid, 255-280. 